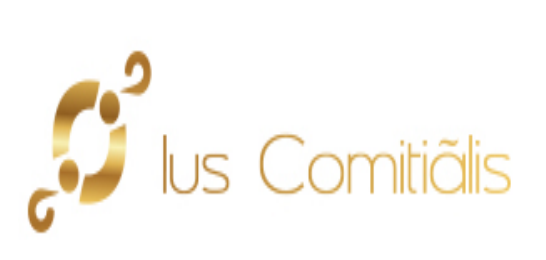

Ius Comitiãlis

ISSN: 2594-1356

iuscomitialis@uaemex.mx

Universidad Autónoma del Estado de México

México

Nova Alpizar, Normalidia

El juicio electoral como medio de impugnación de las sentencias del Tribunal

Electoral del Estado de México en los procedimientos sancionadores

lus Comitiãlis, vol. 2, núm. 4, 2019, Julio-Diciembre, pp. 110-124

Universidad Autónoma del Estado de México

México

DOI: https://doi.org/ 10.36677/iuscomitialis.v2i4.13077

Número completo

Más información del artículo

Página de la revista en redalyc.org 


\section{El juicio electoral como medio de impugnación de las sentencias del Tribunal Electoral del Estado de México en los procedimientos sancionadores The electoral judgment as a means of impugnation of the judgments of the Electoral Court of the State of Mexico in the sanctioning procedures}

Normalidia Nova Alpizar*

Resumen En el presente estudio, desde el garantismo de Ferrajoli, se revisa al juicio electoral como medio de impugnación, que en la práctica se promueve para impugnar las sentencias que dicta el Tribunal Local en los procedimientos sancionadores ordinario y especial, aun cuando este juicio carece de sustento en las leyes electorales, asimismo, se revisan los medios de impugnación en materia electoral, así como la sentencia ST-JE-25/2018, que se generó con motivo de una elección municipal en el Estado de México y se reflexiona acerca de los motivos que existen para que se incluya el juicio electoral como medio de impugnación en la Ley General del Sistema de Medios de Impugnación en Materia Electoral.

Palabras clave Juicio de Revisión Constitucional en materia electoral, Juicio Electoral, medios de impugnación en materia electoral.

Abstract The aim of this paper and from the guarantee of Ferrajoli, the electoral trial is reviewed as a means of challenge, which in practice is promoted to challenge the sentences issued by the Local Court in the ordinary and special sanctioning procedures, even though this trial lacks In the electoral laws, the means of challenge in electoral matters are also reviewed, as well as the ST-JE-25/2018 judgment, which was generated on the occasion of a municipal election in the State of Mexico and reflects on reasons that exist for the electoral trial to be included as a means of challenge in the General Law of the System of Means of Challenge in Electoral Matters.

Key words Trial of Constitutional Review in Electoral Matters, Electoral Judgment, means of contestation in electoral matters.

\footnotetext{
*Licenciada en Derecho por la Universidad Autónoma del Estado de México, Estudios de Especialidad en Derecho Procesal Electoral y de Maestría en Derecho Electoral en el Centro de Formación y Documentación Electoral. En materia político-electoral se desempeña como asesor jurídico. ORCID: https://orcid.org/0000-0003-4201-5772. Correo electrónico: silveral@hotmail.com.
} 


\section{INTRODUCCIÓN}

Los medios de impugnación en materia electoral son los recursos con los que cuentan los ciudadanos, los candidatos independientes y los partidos políticos para acudir ante las autoridades jurisdiccionales a solicitar la restitución de un derecho de la esfera político-electoral que consideran vulnerado.

La Ley General del Sistema de Medios de Impugnación en Materia Electoral (LGSMIME, 2014, art. 3), señala que el sistema de medios de impugnación tiene por objeto garantizar:

a) Que todos los actos y resoluciones de las autoridades electorales en los procesos electorales y de consulta popular se sujeten invariablemente, según corresponda, a los principios de constitucionalidad y de legalidad, y

b) La definitividad de los distintos actos y etapas de los procesos electorales.

El mismo precepto también indica que el sistema de medios de impugnación se integra por:

a) El recurso de revisión, para garantizar la legalidad de actos y resoluciones de la autoridad electoral federal;

b) El recurso de apelación, el juicio de inconformidad y el recurso de reconsideración, para garantizar la constitucionalidad y legalidad de actos y resoluciones de la autoridad electoral federal;

c) El juicio para la protección de los derechos político-electorales del ciudadano;

d) El juicio de revisión constitucional electoral para garantizar la constitucionalidad de actos o resoluciones definitivos y firmes de las autoridades competentes de las entidades federativas para organizar y calificar los comicios o resolver las controversias que surjan durante los mismos;

e) El juicio para dirimir los conflictos o diferencias laborales entre el Instituto Nacional Electoral y sus servidores, y 
f) El recurso de revisión en contra de las resoluciones y sentencias emitidas en los procedimientos especiales sancionadores para garantizar la legalidad de actos y resoluciones de la autoridad electoral federal y del Tribunal Electoral del Poder Judicial de la Federación.

En el ámbito local, el Código Electoral del Estado de México (CEem, 2014, art. 406), regula los juicios y recursos que son procedentes dentro y fuera de los procesos electorales, como son el recurso de revisión, el recurso de apelación, el juicio de inconformidad y el juicio para la protección de los derechos político-electorales del ciudadano local, con lo que evidencia que en ninguno de los ordenamientos citados se encuentra regulado el Juicio Electoral.

El presente estudio se centra en el Juicio Electoral, mismo que carece de fundamento legal como medio de impugnación en contra de las sentencias emitidas por los Tribunales Locales en los procedimientos sancionadores ordinario y especial. En este sentido, existen dos tipos de procedimientos sancionadores, los especiales y los ordinarios, en cuanto a los procedimientos ordinarios, el Reglamento para la Sustanciación de los Procedimientos Sancionadores del Instituto Electoral del Estado de México (RSPSIEEM, 2016, art. 15) señala que:

Las quejas y denuncias que se interpongan, o las iniciadas de oficio por la Secretaría, se tramitarán a través del procedimiento sancionador ordinario en cualquier tiempo cuando se denuncien presuntas infracciones que no sean materia del conocimiento a través del procedimiento especial sancionador. El procedimiento para el conocimiento de las faltas y aplicación de sanciones administrativas podrá iniciarse a instancia de parte o de oficio cuando cualquier órgano del Instituto tenga conocimiento de la comisión de conductas infractoras.

Para la procedencia del procedimiento especial sancionador, el CEEM (2014, art. 482) señala que:

Dentro de los procesos electorales, la Secretaría Ejecutiva del Instituto, iniciará el procedimiento especial establecido por el presente Capítulo, cuando se denuncie la comisión de conductas que:

I. Violen lo establecido en el octavo párrafo del artículo 134 de la Constitución Federal.

II. Contravengan las normas sobre propaganda política o electoral.

III. Constituyan actos anticipados de precampaña o campaña.

La finalidad de estos procedimientos, es que a través de ellos se conozcan actos dentro y fuera de los procesos electorales; los ordinarios procederán en contra de actos que no estén previstos en el procedimiento especial, ya que el especial únicamente se podrá promover contra actos que violen lo señalado en el artículo 134 
constitucional o en su caso, que vulneren las normas de propaganda electoral o que constituyan actos anticipados de campaña y exclusivamente dentro de un proceso electoral.

En estos procedimientos, la conducta denunciada puede calificarse como existente o inexistente y a su vez el CEEM (2014, art. 471) precisa que las conductas encontradas como infractoras, serán sancionadas con multas económicas, amonestación pública e incluso la cancelación del registro de candidatos postulados a puestos de elección popular.

Por lo que, ante la falta de regulación del Juicio Electoral para impugnar las sentencias dictadas dentro de los procedimientos citados, se revisa su naturaleza desde el garantismo de Ferrajoli.

\section{EL GARANTISMO DE LUIGI FERRAJOLI}

El fundamento de todo derecho debe encontrarse en la propia norma jurídica; tal y como son los derechos fundamentales, estos son entendidos como los derechos subjetivos que se encuentran regulados en una norma jurídica, dichos derechos pertenecen a todos los seres humanos reconocidos como persona, de ciudadanos o de personas con capacidad de obrar.

Ferrajoli señala que su teoría se origina a partir del descubrimiento de los derechos fundamentales. En su modelo garantista hace referencia a que debe de haber un cambio estructural en el derecho y la democracia, esta teoría nace a partir de reconocer la existencia de una crisis y que ésta sea de legalidad, de Estado social y en consecuencia de Estado-nación. Considera que la teoría garantista es el mecanismo que ayudará a resolver esa crisis, y que impedirá que existan violaciones por parte de las autoridades, pues debe encaminarse a la creación de un mejor estado de derecho y basado en los derechos fundamentales.

La teoría garantista se sustenta en tres ejes principales (Aguilera y López, citado en Aguilera, 2011, pp. 52-54):

1) Nuevo modelo normativo del derecho. Se caracteriza como un sistema de poder mínimo que concibe los derechos fundamentales como límites, a través de los cuales se maximiza la libertad y se minimiza la arbitrariedad e impunidad por parte de los gobernantes. Con ello propone una reestructuración de la democracia, desglosada en dos dimensiones claras y distintas: democracia formal (relacionada con el procedimiento de toma de decisiones) y democracia sustancial (relativa a los derechos fundamentales).

2) Teoría del derecho y crítica del derecho. El proceso histórico de positivización de los derechos responde al paradigma o modelo tradicional de positivismo jurídico. Sin duda, éste ha sido un referente claro de influencia y continuidad en su visión del garantismo jurídico. La positivación de los derechos fundamentales ha vivido sucesivas etapas históricas, una de ellas ha sido la creación del Estado liberal de derecho que brindó en su momento seguridad jurídica a los 
ciudadanos. En este sentido, Ferrajoli parte inicialmente de la concepción clásica de validez, vigencia y eficacia de las normas jurídicas y propone una modalidad de iuspositivismo crítico frente al iuspositivismo dogmático tradicional.

3) Filosofía político-jurídica. El garantismo como doctrina filosófico-política permite la crítica a las instituciones jurídico-positivas, siguiendo el criterio de la clásica y rígida separación (propia del positivismo) entre derecho y moral o entre validez y justicia. Además, retoma los conceptos sobre las doctrinas autopoyéticas y heteropoyéticas de Luhmann sobre el carácter autorreferencial de los sistemas políticos. Para las doctrinas autopoyéticas, el Estado es un fin y encarna valores ético-políticos de carácter suprasocial y supraindividual a cuya conservación y reforzamiento han de instrumentalizarse los derechos. Por otra parte, según las doctrinas heteropoyéticas, el Estado es considerado un medio legitimado únicamente con el fin de garantizar los derechos fundamentales de los ciudadanos, y políticamente ilegítimo si no los garantiza. El garantismo, entonces, desde un plano filosófico-político, consiste esencialmente en la fundamentación heteropoyética del derecho, separado de la moral en los diversos significados. De esta manera, la deslegitimación externa de las instituciones jurídicas positivas dependerá directamente de la eficacia con la que esos derechos sean cumplidos.

Ferrajoli propone una nueva democracia constitucional, por lo que la dividió en democracia formal, la cual se refiere al cómo es que se deben tomar las decisiones políticas y la sustancial, encaminada a la protección y respeto de los derechos fundamentales, la finalidad de esta teoría es garantizar la eficacia y el cumplimiento de los derechos fundamentales.

$\mathrm{Al}$ ser los derechos fundamentales la base de la teoría garantista, Ferrajoli los define como:

Los Derechos subjetivos (1999, p. 37) corresponden universalmente a todos los seres humanos en cuanto dotados del status de personas o ciudadanos, con capacidad de obrar; entendiendo por derecho subjetivo cualquier expectativa positiva (de prestación) o negativa (de no sufrir lesiones) adscrita a un sujeto por una norma jurídica; y por status la condición de un sujeto, prevista asimismo por una norma jurídica positiva como presupuesto de su idoneidad para ser titular de situaciones y/o autor de los actos que son ejercicio de éstas.

Esta teoría garantista también se aplicó al derecho penal, al respecto Ferrajoli (2006, p. 4) señala que "la ideología jurídica, es una forma de representar, comprender, interpretar y explicar el derecho". Una de las características del garantismo en el ámbito penal, es la desconfianza hacia los poderes, al no existir poderes buenos, porque de los poderes únicamente se pueden esperar abusos y excesos que perjudican al individuo.

Y, en el mismo tenor, señala que la garantía Ferrajoli (2006, p. 5) "es cualquier técnica normativa de tutela de un derecho subjetivo, $\mathrm{O}$ bien, como toda obligación 
correspondiente a un derecho subjetivo, entendiendo por derecho subjetivo toda expectativa jurídica positiva (de prestaciones) o negativa (de no lesiones)".

La teoría garantista vista desde el ámbito penal, aplica por analogía en el ámbito del derecho electoral, porque en materia penal la finalidad del garantismo está dirigida a poner límites a la actuación del poder punitivo del Estado, lo que se traduce en que todos los actos que realice el estado en contra de las personas deben de estar forzosamente normados por las leyes penales, lo que evitará que existan actuaciones arbitrarias por parte del Estado hacia la sociedad, lo mismo sucede en el ámbito electoral, al tener la obligación de garantizar la protección de los derechos fundamentales a través de los medios regulados en la legislación y en consecuencia, que estos sirvan como límite a la autoridad jurisdiccional electoral.

En el ámbito penal, Ferrajoli también sugiere la reserva del Código Penal, es decir, que ninguna medida privativa de la libertad debería de establecerse fuera del propio ordenamiento, esto con la intención de evitar el imponer medidas sin que éstas pasen por el proceso legislativo que prevé la ley, de lo contrario incidiría afectando derechos como la libertad y al ser así, este derecho se vería desprotegido por las leyes vigentes, quedando a la deriva y expuesto a las decisiones de los demás o de las mayorías que en el momento se encuentren en el gobierno. ${ }^{1}$

Con esta propuesta se obliga al legislador a integrar todas las reformas penales dentro del ordenamiento jurídico que corresponda y que esté armonizado con algunos principios, como lo es el de proporcionalidad.

La teoría garantista se basa principalmente en la protección de los derechos fundamentales, y en la obligación que, desde su perspectiva tiene el Estado de protegerlos; toda vez que las crisis a las que refiere Ferrajoli son producto de la falta de respeto y protección de estos derechos, que llevan implícitos todos los demás derechos.

Hay derechos que se han visto vulnerados por la falta de mecanismos de protección; toda vez que para que el actuar del Estado sea válido y conforme a la norma, necesariamente deben de estar reconocidos en las leyes ordinarias que correspondan a la materia y que estas leyes estén legitimadas por el poder al que le haya sido reconocida esta atribución.

Desde esta perspectiva, todas las actuaciones de las autoridades del Estado, de los gobernantes, de los servidores públicos y/o de las instituciones deben tener reconocimiento legal, por esa razón es que Ferrajoli pugna por el respeto de los derechos fundamentales, ya que todo acto debe estar sujeto y reconocido en la ley, lo que obliga a que, el juicio electoral deba también encontrarse dentro de las normas electorales para que pueda promoverse como medio de impugnación y así tener un sustento que permita conocer controversias en materia electoral y, en consecuencia darse una reforma en material electoral que lo integre; la cual debe ser aprobada por el poder legislativo, que es el poder legitimado para aprobarla, al reconocerse se regulará su procedencia, pues de no ser así se estaría lejos de un Estado Constitucional de derecho y de la protección eficaz de los derechos fundamentales que propone Ferrajoli.

La idea que propone Ferrajoli, en cuanto a la reserva del Código Penal, se refiere a la obligación que tiene el legislador, para intentar una acción en contra del gobernador, la cual debe estar plasmada en la ley, lo que lleva a garantizar la protección de sus derechos fundamentales, así como el Estado de derecho. 


\section{LA RELACIÓN ENTRE EL JUEZ Y LA LEY}

La relación que existe entre el juez y la ley, debe de ser armónica en cuanto a lo que dicta el ordenamiento y, esto debe de concordar con lo que en sus procesos resuelva el juez, situación inobservada para el caso de la procedencia del juicio electoral, en virtud de que éste carece de regulación en las leyes electorales.

Al respecto, cabe definir al control de convencionalidad Bustillo (s.f, p. 6) como:

El control de convencionalidad es el mecanismo que se ejerce para verificar que una ley, reglamento o acto de las autoridades del Estado, se ajustan a las normas, los principios y obligaciones de la Convención Americana de Derechos Humanos principalmente, en la que funda la competencia contenciosa de la Corte IDH.

Es una herramienta para le (sic) respeto, la garantía y la efectivización de los derechos descritos en la Convención Americana de Derechos Humanos, asimismo, es de utilidad para la práctica e inmediata elaboración de un ius commune en la región.

Este control se debe ejercer respecto de todos los derechos a los que tiene el ser humano, únicamente por tener esa calidad, para el tema que se aborda la Convención Americana sobre Derechos Humanos (CADH, 1969, art. 8 y 9,) contempla el derecho consistente en las Garantías Judiciales, así como el Principio de Legalidad y de Retroactividad, mandata la protección que se les debe dar a esos derechos que son parte de los derechos fundamentales, por supuesto en el ámbito judicial la obligación del juzgador de ceñir su actuar a lo preceptuado en la norma.

En este contexto surge un conflicto en la relación entre el juez y la ley, por una parte, atender la petición del ciudadano, de los candidatos independientes e incluso de los partidos políticos encaminada a la protección de sus derechos, y por la otra, su función de autoridad jurisdiccional, este conflicto deriva de la obligación que tiene el juzgador de observar lo previsto en cada uno de los casos, lo que lo coloca en imposibilidad de resolver controversias electorales a través de un juicio ilegal, acto que el juzgador omitió llevar a cabo en la ST-JE-25/2018.

El juez, además de la obligación jurídica, también tiene una obligación moral de someter sus criterios a lo previsto en las leyes del Estado de derecho, este actuar habrá de ser armónico con el Estado Constitucional, que regula las conductas de la sociedad a través de las normas establecidas para esto, precisamente a lo indicado en la Constitución Política de los Estados Unidos Mexicanos (CPEUM).

\section{LOS MEDIOS DE IMPUGNACIÓN EN MATERIA ELECTORAL}

Dentro del marco normativo de los medios de impugnación, como ordenamiento máximo, está la regulación constitucional (CPEUM, 2019, art. 41, Base VI, art. 
99, fracción V), que mandata que el sistema de medios de impugnación tiene la finalidad de garantizar que en los actos y resoluciones emitidos por las autoridades electorales jurisdiccionales, prevalezcan los principios de legalidad y constitucionalidad y, a través de estos medios se pretende agotar el principio de definitividad en materia electoral. Esto con la única intención de brindar protección a los derechos políticos electorales del ciudadano como lo son la libertad de expresión, el derecho de votar y ser votado, el derecho de asociación y también a través de estos medios los partidos políticos y los candidatos independientes podrán acudir ante las autoridades electorales a solicitar la reparación de algún derecho que se considere vulnerado.

El sistema electoral mexicano está diseñado para que cada una de las acciones emitidas por tribunales administrativos o jurisdiccionales puedan ser controvertidos a través de los medios de impugnación reconocidos en la ley y que, por supuesto, tienen delimitada su procedencia, así como los requisitos que reviste. Se retoma al juicio electoral y el juicio de revisión constitucional electoral, al ser los juicios que de manera práctica se han promovido para controvertir las sentencias dictadas dentro los procedimientos sancionadores ordinario y especial.

El juicio de revisión constitucional electoral (Glosario del TEPJF) "es el medio de impugnación que los partidos políticos pueden presentar para impugnar los actos o resoluciones de las autoridades electorales de las entidades federativas", por su parte, Galván (1997, p. 332) lo define como:

La vía constitucional y legalmente establecida en favor de los partidos políticos, para controvertir la constitucionalidad y legalidad de los actos y resoluciones definitivas, emitidos por las autoridades electorales, administrativas y jurisdiccionales de las entidades de la federación mexicana, responsables de realizar (sic) los procedimientos electorales locales y municipales o, en su caso, de resolver los litigios de ellos emergentes.

La finalidad de este juicio es el ejercicio del control de constitucionalidad en materia electoral, a través de las Salas Regionales del Tribunal Electoral del Poder Judicial de la Federación, mismas que actúan como revisor del actuar de los tribunales locales, con el objeto de que sus sentencias se apeguen al marco constitucional y legal.

El juicio citado fue reconocido en la legislación electoral a raíz de la reforma constitucional de 1996, como mecanismo de revisión constitucional electoral, en las decisiones definitivas e inatacables de las autoridades encargadas de organizar y calificar los procesos electorales locales, para fortalecer las vías jurídicas en lo que se ha llamado judicialización de la política.

Después de haber pasado por estas reformas electorales (LGSMIME, 2018, Art. 86), actualmente, la ley señala que el juicio de revisión constitucional electoral es procedente en los supuestos:

El juicio de revisión constitucional electoral sólo procederá para impugnar actos o resoluciones de las autoridades competentes de las entidades federativas para organizar y calificar los comicios locales o resolver las controversias que surjan durante los mismos, siempre y cuando se cumplan los requisitos siguientes: 
- Que sean definitivos y firmes;

- Que violen algún precepto de la Constitución Política de los Estados Unidos Mexicanos;

- Que la violación reclamada pueda resultar determinante para el desarrollo del proceso electoral respectivo o el resultado final de las elecciones;

- Que la reparación solicitada sea material y jurídicamente posible dentro de los plazos electorales;

- Que la reparación solicitada sea factible antes de la fecha constitucional o legalmente fijada para la instalación de los órganos o la toma de posesión de los funcionarios electos; $y$

- Que se hayan agotado en tiempo y forma todas las instancias previas establecidas por las leyes, para combatir los actos o resoluciones electorales en virtud de los cuales se pudieran haber modificado, revocado o anulado.

- El incumplimiento de cualquiera de los requisitos señalados en este artículo tendrá como consecuencia el desechamiento de plano del medio de impugnación respectivo.

El juicio de revisión constitucional electoral se promueve para controvertir temas de constitucionalidad, más que de legalidad; además una de las características que reviste la ley para su procedencia, es que los agravios planteados sean determinantes por cuanto al acto que se reclame, situación que para el caso de impugnar sentencias sobre procedimientos especiales y sancionadores en sentencias dictadas por los Tribunales Locales, no sucede en algunos casos, además de ser un juicio de estricto derecho, mismo que inadmite más reclamos que los ya planteados en primera instancia, en virtud de que la función de las Salas en estos procedimientos es actuar como órgano revisor de las determinaciones de los tribunales locales.

Sobre el juicio electoral existe un precedente en su surgimiento contenido en los Lineamientos para la Identificación e Integración de los Expedientes del Tribunal Electoral del Poder Judicial de la Federación, al ser el documento que señala la existencia de este juicio electoral.

En los Lineamientos Generales para la Identificación e Integración de Expedientes del Tribunal Electoral del Poder Judicial de la Federación (LGIIETEPJF, 2014, pp. 2-3) únicamente se enuncia que la materia electoral es dinámica y que, por esta razón, en ocasiones se carece de un medio de impugnación a través del cual se pueda conocer algún asunto, por lo que desde su perspectiva y en aras de brindar la protección más amplia de un derecho determinaron la integración del Juicio Electoral, al respecto, se precisa:

No obstante, la denominación de dichos expedientes no resulta idónea para identificarlos, toda vez que los asuntos denominados asuntos generales se integran con todas aquellas promociones o comunicaciones de carácter jurisdiccional que no encuentran cavidad como alguno de los juicios o recursos 
previstos en la normativa electoral y conforme a los presentes lineamientos de manera tal que sea difícil la identificación de cuales asuntos generales son efectivamente medios de impugnación; por tanto, se estima conveniente que se denomine de manera genérica "juicio electoral" para conocer el planteamiento respectivo, el cual deberá tramitarse en términos de las reglas generales previstas para los medios de impugnación establecidas en la ley adjetiva electoral federal.

Al establecer la Sala Superior esta determinación se ordenó su cumplimiento a las Salas Regionales, sin existir otro sustento legal, más que los Lineamientos ya invocados.

Existen asuntos resueltos por la Sala Superior, en la vía del juicio electoral, en los que justifica el entrar al estudio de fondo, tal como sucedió en el expediente SUP-JE-74/2018 (STEPJF, 20 de diciembre de 2018), que refiere:

También es criterio de la Sala Superior, que la posible ausencia de un juicio o recurso local específico no es obstáculo para resolver los conflictos y garantizar los derechos. Por tanto, en su caso, el Tribunal Electoral deberá implementar un medio acorde a los reclamos que aduce el instituto local, en el que se observen las formalidades del procedimiento, a fin de conocer y resolver en plenitud de jurisdicción la controversia planteada.

Por su parte, la sentencia emitida por la Sala Superior SUP-JRC-158/2018 (STEPJF, 22 de agosto de 2018), entró al análisis de cada uno de los medios de impugnación y a su vez señala que no existe medio idóneo para conocer sobre las impugnaciones relacionadas con las sentencias emitidas por los Tribunales electorales locales, y que la jurisprudencia que existe al respecto ya está rebasada, porque de lo contrario se actualizaría una contradicción de criterios, esta misma sentencia también refiere: "sin embargo con la finalidad de dar congruencia al nuevo sistema de competencias en la sustanciación y resolución de los procedimientos especiales sancionadores, se estima que el juicio electoral es la vía idónea para conocer de esas determinaciones, con independencia de que se esté en presencia de una determinación de un Tribunal Local como primera instancia o no".

En la sentencia citada se advierte que la propia autoridad reconoce que no existe medio previsto en la ley, para conocer a través de este juicio, pero también señala que el Juicio de Revisión Constitucional Electoral no cumple los requisitos procesales para entrar al estudio de fondo de una sentencia dictada por un Tribunal Local, al carecer de elementos para acreditar los extremos de procedencia y estos sean controvertidas a través de este juicio. 
REVISIÓN DE LA SENTENCIA ST-JE-25/2018

Esta sentencia fue emitida con motivo de que, el Partido Revolucionario Institucional interpusiera un juicio donde el acto impugnado era la sentencia emitida por el Tribunal Electoral del Estado de México, dictada el treinta de octubre de dos mil dieciocho, dentro del procedimiento especial sancionador identificado con la clave PES/302/2018, en la que señalaba como agravio la Indebida valoración de la conducta infractora, ya que el actor consideraba que la responsable había valorado de manera incorrecta el hecho de que el candidato denunciado, durante un evento de carácter proselitista portara un cristo, por un instante, lo que desde su perspectiva se actualizaba la utilización de símbolo religiosos, hecho que prohíben las leyes electorales.

Además de que, al realizar estos actos le daba cierta ventaja sobre los demás contendientes que estaban participando para el mismo cargo de elección popular, por lo que el partido actor sostenía que se debía haber sancionado, y a su juicio el Tribunal Local había valorado incorrectamente esa acción.

De la revisión de esta sentencia (STEPJF, 22 de noviembre de 2018), específicamente en el apartado denominado "PRIMERO. Jurisdicción y competencia", se lee:

Cabe mencionar que la vía denominada juicio electoral fue producto de los Lineamientos Generales para la Identificación e Integración de Expedientes del Tribunal Electoral del Poder Judicial de la Federación, en los cuales se expone que en virtud del dinamismo propio de la materia, ha originado que en ocasiones no exista un medio de impugnación específico para hacer valer la afectación derivada de algún acto o resolución en materia electoral y, para esos casos, los lineamientos referidos inicialmente ordenaban formar los Asuntos Generales, pero a raíz de su última modificación, ahora indica que debe integrarse un expediente denominado juicio electoral, el cual debe tramitarse en términos de las reglas generales previstas para los medios de impugnación establecidas en la Ley General del Sistema de Medios de Impugnación en Materia Electoral.

Derivado de esta determinación se ordena que se conozca este juicio electoral que deviene de la resolución recaída en una sentencia dictada dentro un procedimiento especial, ${ }^{2}$ es decir, se ha demostrado que el juicio electoral está falto de regulación jurídica en una ley electoral que esté aprobada por el órgano legitimado para expedirla, y que para su conocimiento a través de esta vía sólo se está atendiendo a una orden emitida por una autoridad jurisdiccional superior en materia electoral.

PES/302/2018, incoado con motivo de las quejas presentadas por el Partido Revolucionario Institucional, a través de su representación ante los Consejos Municipales del Instituto Electoral del Estado de México, con sede en Malinalco y Ocuilan, en contra de Roberto Cabañas Poblete y Félix Alberto Linares González, en su momento candidatos a la Presidencia Municipal en dichas demarcaciones, respectivamente, así como de la Coalición "Por el Estado de México al Frente", como instancia postulante, por conductas que en su estima, constituyen infracciones a la normativa electoral, derivado de la utilización de símbolos religiosos en actos de campaña. 


\section{INCLUSIÓN DEL JUICIO ELECTORAL EN LA LEY GENERAL DEL SISTE- MA DE MEDIOS DE IMPUGNACIÓN EN MATERIA ELECTORAL}

Desde la mirada de Ferrajoli, el entrar al estudio de una controversia electoral a través del juicio electoral, sería improcedente, al estar distante de la norma legal aplicable, por lo que habrá de integrarse al ordenamiento electoral, esto con el ánimo de garantizar la protección de los derechos fundamentales del individuo, ya que de lo contrario la autoridad jurisdiccional que conoce del medio de impugnación estaría actuando de manera arbitraria emitiendo una sentencia a través de un medio que carece de sustento legal.

De ahí, nace la interrogante ¿Qué sucedería si las partes involucradas acudieran a una instancia superior señalando como agravio la violación de los artículos 14, 16 y $17^{3}$ de la Constitución Política de los Estados Unidos Mexicanos? En los preceptos citados se consigna la obligación que tiene las autoridades, tanto administrativas como jurisdiccionales de fundar y motivar las sentencias que emitan, además de un tutela judicial efectiva; porque por un lado, la propia Constitución Federal en el artículo 1o señala la obligación de las autoridades de proteger en todo momento los derechos humanos de los ciudadanos, sin embargo, tomando como base experiencia en las sentencias que emiten los tribunales jurisdiccionales y a las propios ordenamientos jurídicos, en todo proceso, siempre existe un ganador y un perdedor ${ }^{4}$ así pues, ¿De qué manera se puede equilibrar para que deje de existir la vulneración de los derechos de una de las dos partes?, debe ser a través de procedimientos legitimados por la ley, sin dejar lugar a duda del actuar judicial, ya que para el caso en concreto la sentencia está dirigida a imponer una sanción, y en el momento en que la parte afectada acuda a instancias superiores, el motivo de su agravio será que se le está imponiendo una sanción a través de un juicio inexistente en la ley, por lo que se están violentando sus derechos fundamentales y en consecuencia se estaría actuando fuera de la ley, conculcando el Estado de Derecho.

\section{REFLEXIONES FINALES}

- El sistema de medios de impugnación en materia electoral está diseñado para brindar protección a los derechos políticos electorales de los partidos políticos, de los ciudadanos, de los candidatos independientes, y de todo aquel que consideren que de alguna forma se conculca su esfera de derechos político-electorales; también son concebidos como los mecanismos que garanticen los principios constitucionales tales como la libertad, autenticidad y periodicidad, principios que forman y rigen al sistema elec-

\footnotetext{
La tutela judicial efectiva implica el derecho público subjetivo y se refiere que la efectividad judicial no se colma al momento de emitir una sentencia, sino que es, hasta el momento en que esa sentencia se ejecuta en favor de quien haya resultado favorable.

PRIMERO. Se revoca la sentencia impugnada.

SEGUNDO. Se vincula al Tribunal Electoral del Estado de México, para que imponga las sanciones que considere le corresponde al excandidato Félix Alberto Linares González y a la Coalición "Por el Estado de México al Frente", integrada por los partidos políticos Acción Nacional, de la Revolución Democrática y Movimiento Ciudadano, por las razones expuestas en el último considerando del presente fallo.

Para tal efecto, se otorga al referido tribunal un plazo de cinco días contados a partir de la notificación de la presente sentencia, y hecho lo anterior, informe a esta Sala Regional dentro del término de veinticuatro horas siguiente (resaltado añadido).
} 
toral mexicano, y que son claves para la organización y calificación de las elecciones.

- El juicio electoral, es un medio inexistente en la Ley, en tanto su naturaleza jurídica y procedencia legal se encuentran indefinidas, por lo que desde la teoría garantista de Ferrajoli, que pugna por la protección de los derechos fundamentales, es inconstitucional e ilegal el dictar sentencias a través de este juicio.

- Los Tribunales electorales jurisdiccionales, particularmente la Sala Regional Toluca como órgano revisor del actuar de los Tribunales Electorales Locales, conoce impugnaciones a través del Juicio Electoral, el cual dista de regularse en la ley.

- El Juicio de Revisión Constitucional Electoral, tiene su procedencia en la Ley General del Sistema de Medios de Impugnación, sin embargo, esta procedencia va más allá de la legalidad, al ser este un juicio de estricto derecho.

- Las autoridades jurisdiccionales electorales conocen por la vía del Juicio electoral impugnaciones en contra de las sentencias dictadas por el Tribunal Electoral del Estado de México, anteriormente estas impugnaciones eran resueltas a través del Juicio de Revisión Constitucional Electoral en materia electoral en segunda instancia y fue hasta mediados del 2018, que en la praxis esas mismas sentencias se recurren mediante el Juicio Electoral.

- Ante la presencia de este vacío en la ley, el poder legislativo federal es el legitimado para la discusión y la aprobación de las reformas electorales, esta función legislativa tiene por objeto establecer los presupuestos procesales y requisitos a cumplir en el juicio electoral para su procedencia, de lo contrario se incumpliría la propia ley al entrar al estudio de medios de impugnación inexistentes, ya que si bien es cierto, la vía para controvertir las sentencias referidas no es el juicio de revisión constitucional electoral en razón de las características que reviste para su procedencia, también lo es que hasta este momento tampoco lo es el juicio electoral, al carecer de reconocimiento legal y tener indefinida su procedencia.

\section{REFERENCIAS}

1. Aguilera, R. (coord.) (2011). Nuevas perspectivas y desafíos en la protección de los derechos humanos. México: IIJ-UNAM.

2. Bustillo, R. (s.f.). El control de convencionalidad. La idea del bloque de constitucionalidad y su relación con el control de constitucionalidad en materia electoral. Líneas jurisprudenciales. Tribunal Electoral del Poder Judicial de la Federación. 
3. Constitución Política de los Estados Unidos Mexicanos (CPeum). Cámara de Diputados, Ciudad de México, 5 de febrero de 1917.

4. Código Electoral del Estado de México (CEEM). Cámara de Diputados Locales, Toluca de Lerdo, Estado de México, 28 de junio de 2014.

5. Convención Americana sobre Derechos Humanos (CADH). San José, Costa Rica 7 al 22 de noviembre de 1969.

6. Ferrajoli, L. (julio-diciembre 2006). Sobre los derechos fundamentales. Cuestiones constitucionales revista mexicana de derecho constitucional, número 15. Recuperado de https://revistas.juridicas.unam.mx/ index.php/cuestiones-constitucionales/article/view/5772/7600.

7. Ferrajoli, L. (2006). Garantismo penal. Series Estudios jurídicos 34. Colección Facultad de Derecho. UnAm.

8. Ferrajoli, L. (1999). Derechos fundamentales, Derechos y garantías. La ley del más débil. Madrid: Trotta.

9. Galván, F. (1997). Derecho Procesal Electoral Mexicano. México: Gama Sucesores.

10. Glosario del Tribunal Electoral del Poder Judicial de la Federación, letra J. Recuperado de https://www.te.gob.mx/front/glossary/.

11. Ley General del Sistema de Medios de Impugnación en Materia Electoral (LgSmime). Instituto Electoral del Estado de México, 22 de noviembre de 1996.

12. Lineamientos para la Identificación e Integración de los Expedientes del Tribunal Electoral del Poder Judicial de la Federación (2014). Sala Superior del Poder Judicial de la Federación. Recuperado de https:// www.te.gob.mx/sites/default/files/acuerdo_acta/archivo/lineamientos_2014_0.pdf.

13. México. Tribunal Electoral del Poder Judicial de la Federación (TEPJF) (Sala) [internet]. Sentencia SUP-JE-74/2018, de 20 de diciembre de 2018. Recuperado de https://www.te.gob.mx/buscador/.

14. México. Tribunal Electoral del Poder Judicial de la Federación (TEPJF) (Sala) [internet]. Sentencia SUP-JE-158/2018, de 22 de agosto de 2018. Recuperado de https://www.te.gob.mx/buscador/.

15. México. Tribunal Electoral del Poder Judicial de la Federación (TEPJF) (Sala) [internet]. Sentencia ST-JE-25/2018, de 22 de noviembre de 2018. Recuperado de https://www.te.gob.mx/buscador/. 
16. México. Tribunal Electoral del Estado de México (TeEm) (Tribunal) [internet]. Sentencia PES/302/2018, de 26 de noviembre de 2018. Recuperado de http://www.teemmx.org.mx/sentencias/proceso_esp_san. php.

17. Reglamento para la Sustanciación de los Procedimientos Sancionadores del Instituto Electoral del Estado de México (RSPSIEEM). Consejo General del Instituto Electoral del Estado de México, aprobado mediante acuerdo IEEM/CG/71/2016, Toluca de Lerdo, Estado de México, 02 de septiembre de 2016 . 